\title{
Vitamin D Binding Protein Genotype and Osteoporosis
}

\author{
Yue Fang · Joyce B. J. van Meurs · Pascal Arp · \\ Johannes P. T. van Leeuwen · Albert Hofman . \\ Huibert A. P. Pols · André G. Uitterlinden
}

Received: 20 August 2008/Accepted: 16 April 2009/Published online: 2 June 2009

(C) The Author(s) 2009. This article is published with open access at Springerlink.com

\begin{abstract}
Osteoporosis is a bone disease leading to an increased fracture risk. It is considered a complex multifactorial genetic disorder with interaction of environmental and genetic factors. As a candidate gene for osteoporosis, we studied vitamin D binding protein (DBP, or groupspecific component, Gc), which binds to and transports vitamin $\mathrm{D}$ to target tissues to maintain calcium homeostasis through the vitamin D endocrine system. DBP can also be converted to DBP-macrophage activating factor (DBPMAF), which mediates bone resorption by directly activating osteoclasts. We summarized the genetic linkage structure of the DBP gene. We genotyped two singlenucleotide polymorphisms $($ SNPs, rs7041 = Glu416Asp and rs4588 $=$ Thr420Lys) in 6,181 elderly Caucasians and investigated interactions of the DBP genotype with vitamin $\mathrm{D}$ receptor (VDR) genotype and dietary calcium intake in relation to fracture risk. Haplotypes of the DBP SNPs correspond to protein variations referred to as Gc1s (haplotype 1), Gc2 (haplotype 2), and Gc1f (haplotype3). In a subgroup of 1,312 subjects, DBP genotype was found to be associated with increased and decreased serum $25-(\mathrm{OH}) \mathrm{D}_{3}$ for haplotype $1\left(P=3 \times 10^{-4}\right)$ and haplotype $2(P=3 \times$ $\left.10^{-6}\right)$, respectively. Similar associations were observed for
\end{abstract}

Y. Fang · J. B. J. van Meurs · P. Arp ·

J. P. T. van Leeuwen - H. A. P. Pols · A. G. Uitterlinden $(\square)$

Genetic Laboratory, Room Ee575, Department of Internal

Medicine, Erasmus Medical Center, P.O. Box 1738, 3000 DR

Rotterdam, The Netherlands

e-mail: a.g.uitterlinden@erasmusmc.nl

Y. Fang

e-mail: fangnl@yahoo.com

A. Hofman - H. A. P. Pols - A. G. Uitterlinden

Department of Epidemiology, Erasmus Medical

Center, Rotterdam, The Netherlands
1,25- $(\mathrm{OH})_{2} \mathrm{D}_{3}$. The DBP genotype was not significantly associated with fracture risk in the entire study population. Yet, we observed interaction between DBP and VDR haplotypes in determining fracture risk. In the DBP haplotype 1-carrier group, subjects of homozygous VDR block 5-haplotype 1 had 33\% increased fracture risk compared to noncarriers $(P=0.005)$. In a subgroup with dietary calcium intake $<1.09 \mathrm{~g} /$ day, the hazard ratio $(95 \%$ confidence interval) for fracture risk of DBP hap1-homozygote versus noncarrier was 1.47 (1.06-2.05). All associations were independent of age and gender. Our study demonstrated that the genetic effect of the DBP gene on fracture risk appears only in combination with other genetic and environmental risk factors for bone metabolism.

Keywords DBP · VDR - Haplotype - Calcium intake · Fracture

Osteoporosis is defined as a reduction in bone mass deterioration of bone microarchitecture, resulting in increased bone fragility and increased fracture risk [1]. It is a complex disorder with interaction between environmental (e.g., low calcium intake) and genetic factors. Several genetic association studies have demonstrated a relationship between polymorphisms of candidate genes with decreased bone mineral density (BMD) and increased fracture risk [2-7].

A deficiency of vitamin $\mathrm{D}$ results in rickets in children and osteomalacia in adults and increases risk of osteoporosis [8]. Vitamin D binding protein (DBP) was initially named group-specific component (Gc) and is a serum protein with differential functions. Two functions of DBP involve skeletal metabolism: The first one is through the 
vitamin D endocrine system. Vitamin D is an important cofactor of calcium absorption in intestine and reabsorption in kidney, which plays an essential role in regulating serum calcium and phosphate homeostasis as well as bone metabolism. DBP binds to vitamin D metabolites (e.g., 25-hydroxyvitamin $\mathrm{D}_{3}\left[25(\mathrm{OH}) \mathrm{D}_{3}\right]$, the major circulating metabolite, and 1,25-dihydroxyvitamin $\mathrm{D}_{3}\left[1,25(\mathrm{OH})_{2} \mathrm{D}_{3}\right]$, the active form of vitamin $\mathrm{D}$ ) at the sterol binding domain (domain I in Fig. 1a) [9]; transports vitamin D to liver, kidney, bone, and other target tissues; and stores and prolongs the half-life of the circulating vitamin D metabolites [10]. Vitamin D metabolites are strongly and positively correlated to DBP levels in serum [11, 12].

The vitamin D receptor (VDR) mediates the action of the vitamin $\mathrm{D}$ endocrine system in calcium homeostasis and bone metabolism. In a previous study, we demonstrated that the haplotype 1 allele of linkage disequilibrium (LD) block 5, including variations in the $3^{\prime}$-untranslated region (UTR) of the VDR gene, are associated with increased fracture risk. This allele decreases the VDR mRNA level by $15 \%$ in osteoblast cells [13].

Besides its role in vitamin D metabolism, serum DBP can also be converted to a DBP-macrophage activating factor (DBP-MAF) by the deglycosylation of DBP at the non-sterol binding domain (domain III in Fig. 1a), which involves the osteoclast activating domain $[14,15]$. DBP-
MAF plays a role in osteoclast differentiation [16] and mediates bone resorption by directly activating osteoclasts [14]. DBP-MAF-treated osteopetrosis rats have increased number and activity of osteoclasts and decreased bone mass [17]. Hence, the contribution of DBP to bone metabolism is not only through assisting the vitamin D endocrine system but also directly influencing bone resorption. In addition, there is evidence to suggest an interaction of DBP with calcium intake. The number of osteoclasts significantly increases when rats are in a calcium deficiency condition, and the osteoclast number returned to a similar level as control groups after calcium or phosphorus replenishment $[18,19]$. Thus, both DBPMAF and low calcium intake can influence osteoclast number and activity.

Thus, DBP and the vitamin D-VDR system might influence bone resorption (via osteoclasts) and bone formation (via osteoblasts), respectively, which could result in osteoporosis.

The three most commonly studied protein variations are identified by two polymorphisms in exon 11: a G/A substitution at codon 416 (E416D), leading to a Glu/Asp amino acid change, and a C/A substitution at codon 420 (T420K), leading to a Thr/Lys amino acid change [20]. Haplotypes of the nucleotide changes result in the protein isoforms Gc1s, Gc2, and Gc1f (Fig. 1b). Recently, two

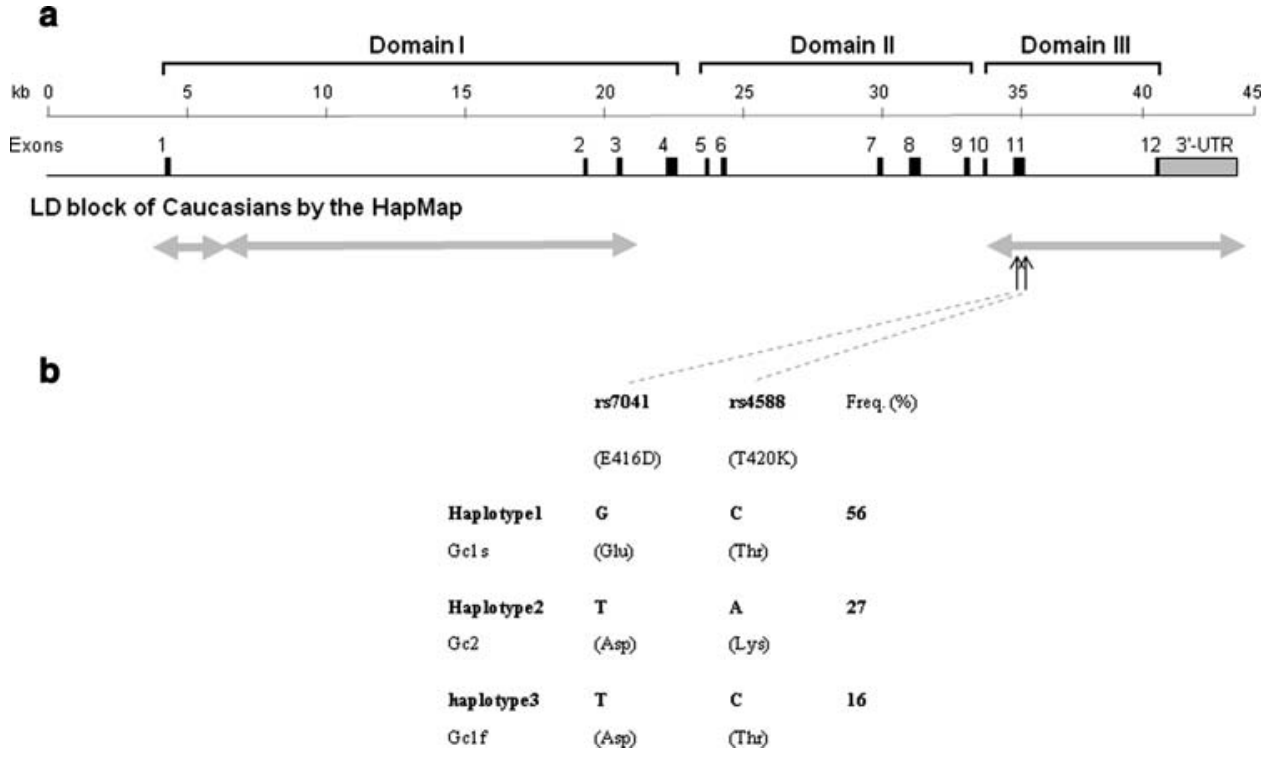

Fig. 1 Functional domain of the Gc protein and haplotype structure and allele frequencies in different ethnic populations. a The triple domain structure of the Gc protein and the haplotype structure of the $\mathrm{DBP}(\mathrm{Gc})$ gene. Three domains of the Gc protein are shown at top; domain I is the vitamin D binding domain. Domains II and III are non-sterol binding activity domains. Domain III is related to macrophage/osteoclast activating activity. In the middle we present the genomic structure of the DBP gene. In the lower panel, we present the haplotype structures of the DBP gene in a Caucasian population according to the HapMap data. The gray double-headed arrows indicate LD blocks in a population. The LD structure is defined according to 50 genotyped SNPs of the population in the region from the HapMap data. b Haplotype structure and allele frequency comparison according to SNPs E416D (rs7041) and T420K (rs4588) in exon 11 of the DBP gene. Vertical arrows indicate two nonsynonymous SNPs. Haplotype and protein variation alleles are in the left panel. Allele frequencies of haplotypes were calculated in the Rotterdam Study population 
studies demonstrated a relationship between a DBP haplotype (or protein isoform, Gc1) with decreased BMD and increased fracture risk in Japanese and Caucasian populations [21, 22].

Since both DBP and VDR gene are involved in the vitamin $\mathrm{D}$ endocrine pathway, which is one of the key systems of osteoporosis, no studies so far have addressed the genetic interaction between VDR and DBP gene variants on osteoporosis risk; and neither has the interaction been studied between serum level of DBP and dietary calcium intake in relation to osteoporosis. In this study, we studied genetic variants in the DBP gene in relation to osteoporosis risk, gene-gene interaction (DBP-VDR, the interaction of genes encoding vitamin $\mathrm{D}$ transporter and receptor in the vitamin D endocrine pathway), as well as gene-environmental interaction (DBP gene variants vs. dietary calcium intake, both involving osteoclast activity) in relation to the risk of osteoporosis in a large-scale population-based cohort (the Rotterdam Study).

\section{Materials and Methods}

\section{Subjects}

\section{The Rotterdam Study Population}

The Rotterdam Study is a single-center prospective population-based cohort study and includes 7,983 ( $>55$ years) Caucasian individuals, with 3,105 men (38.9\%) and 4,878 women $(61.1 \%)$, to analyze the determinants and prognosis of chronic and disabling diseases in the elderly [23]. The baseline measurements were performed between 1990 and 1993. For the current study, 6,580 DNA samples (82.4\% of the whole cohort population) were available, and 6,181 individuals were successfully genotyped for DBP SNPs, including 6,009 subjects being successfully genotyped for both DBB and VDR genotypes. For 4,747 out of 6,181 subjects, data on dietary calcium intake were available. Of the 6,181 subjects, 5,931 had baseline measurements of $\operatorname{BMD}\left(\mathrm{g} / \mathrm{cm}^{2}\right)$. At baseline, for 1,317 (of 6,181) subjects we measured serum vitamin $\mathrm{D}$ level.

\section{DNA Isolation and Genotyping}

Genomic DNA was isolated from peripheral venous blood specimens according to standard protocols. In the DBP gene we genotyped two single nucleotide polymorphisms (SNPs) in exon 11, E416D and T420K, which change the amino acid sequence at codons 416 and 420 , respectively. The genotyping was detected with Taqman assays from Applied Biosystems (ABI; Foster City, CA). The assay mixes (including unlabeled PCR primers, $\mathrm{FAM}^{\mathrm{TM}}$ and
VIC $^{\circledR}$ dye-labeled TaqMan MGB probes) of Assaysby-Design ${ }^{\mathrm{TM}}$ were designed and supported by ABI. The reaction system contained $2 \mathrm{ng}$ of dried genomic DNA, 2.5 $\mu \mathrm{L}$ of TaqMan ${ }^{\circledR}$ Universal PCR Master Mix, No AmpErase $^{\circledR} \mathrm{UNG}(2 \times), 0.125 \mu \mathrm{L}(40 \times)$, or $0.0625 \mu \mathrm{L}(80 \times)$ of Assay Mix, and adjusted Milli-Q $\mathrm{H}_{2} \mathrm{O}$ in a total volume of $5 \mu \mathrm{L}$. The reaction conditions consisted of an initial step at $95^{\circ} \mathrm{C}$ for $10 \mathrm{~min}$, followed by 40 cycles at $92^{\circ} \mathrm{C}$ for $15 \mathrm{~s}$ and $60^{\circ} \mathrm{C}$ for $60 \mathrm{~s}$ in a 384-well plate using PCR machines, ABI Prism ${ }^{\circledR} 7900 \mathrm{HT}$, ABI GeneAmp ${ }^{\circledR}$ PCR system 9700, or PTC-225 Peltier Thermal Cycler (MJ Research, Watertown, MA). The genotyping results were analyzed by end point reading in the ABI Prism 7900HT, determined independently by two operators; and 5\% random samples were regenotyped to check for genotyping errors. No inconsistencies were observed.

\section{LD and Haplotype Analyses}

We first compared LD structures of the DBP gene for the Caucasian population with the HapMap database (Release 23a/phase II March 2008, on NCBI B36, dbSNP b126) [24] (Fig. 1a). We selected SNPs with a minor allele frequency $>10 \%$, and identified 50 SNPs. (The haplotypes of E416D and T420K SNPs in the Rotterdam Study population were generated by the PHASE program [25]).

\section{Clinical Data for the Association Study}

Information on medical history, dietary habits, age at menopause, and smoking was obtained with a computerized questionnaire during a home interview at baseline. Intakes of calcium and total energy were calculated by food-frequency questionnaire (based on all food and drinks consumed in 1 month) with the use of Dutch food-composition tables. We calculated the total dietary energy intake and adjusted dietary calcium intake for all individuals. Anthropometric measurements of participants were obtained at the research center. Height $(\mathrm{cm})$ and weight $(\mathrm{kg})$ were measured in the standing position in indoor clothing without shoes, and all height measurements were obtained by a research assistant using a standard wallmounted station-meter. Body mass index (BMI) was calculated as weight $(\mathrm{kg})$ divided by height squared $\left(\mathrm{m}^{2}\right)$. BMD $\left(\mathrm{g} / \mathrm{cm}^{2}\right)$ was determined by dual-energy X-ray absorptiometry (DXA, Lunar DPX-L densitometer; Lunar Radiation, Madison, WI) at the femoral neck and lumbar spine (vertebrae L2-L4) as described before [26].

\section{Assessment of Fracture}

We defined fracture as described before [5, 27, 28]. All fractures were confirmed by general practitioners or 
hospitals and included hip, vertebral, wrist, and other fractures but excluded head, foot, hand, and pathological postprocedural skull and face fractures. The incidence of fracture was considered as new cases diagnosed during the follow-up period $(7.4 \pm 3.3$ years). The latest follow-up period ended January 1, 2002.

\section{Vitamin D Measurement}

A total of $50 \mu \mathrm{L}$ serum obtained at baseline was stored at $-20^{\circ} \mathrm{C}$ and used for the quantitative determination of total (free and bound form) $25(\mathrm{OH}) \mathrm{D}_{3}$ and $1,25(\mathrm{OH})_{2} \mathrm{D}_{3}$ levels with radioimmunoassay kits from Immunodiagnostic Systems (Boldon, UK). The assays for vitamin D measurement are routine assays used in the clinic for patient diagnostics. Three concentrations of $25(\mathrm{OH}) \mathrm{D}_{3}$ and $1,25(\mathrm{OH})_{2} \mathrm{D}_{3}$ were tested with an average $\mathrm{VC}$ of 5.7 and $6.6 \%$, respectively.

\section{Statistical and Association Analyses}

All genotyping results were tested for Hardy-Weinberg equilibrium (HWE). We applied one-way analysis of variance (ANOVA) to investigate the relationship between genotypes and age, height, weight, BMD, BMD loss, bone geometry variables, serum vitamin $\mathrm{D}$ level, dietary calcium intake, and other continuous outcomes. We employed the Pearson $\chi^{2}$ test and calculated the hazard ratio (HR) and 95\% confidence interval $(95 \% \mathrm{CI})$ with the Cox regression model to investigate the relationship between incidence of clinical fracture and haplotypes of the DBP gene. To check the proportional hazard assumption of the Cox model, we plotted the Kaplan-Meier observed hazard curve and compared it to the Cox predicted curve. When the predicted and observed values were close together, the proportional hazard assumption had not been violated. Both analysis of covariance (ANCOVA) and Cox models were adjusted for potential confounders, such as age, gender, height, weight, BMD, and dietary calcium intake. We also stratified the analyses by gender and high/low calcium intake according to the median, tertiles, and quartiles of dietary calcium intake in the study population. The genegene and gene-environmental interactions of VDR genotype and calcium intake with DBP genotype for fracture risk were first estimated in linear regression models with adjustment for age and gender; we then compared (1) the pattern difference of the association of VDR genotype with fracture risk by DBP genotypes and (2) the pattern difference of the association of DBP haplotype with fracture risk by low or high calcium intake groups. All statistical analyses of the association study were carried out with the SPSS software package (version 14; SPSS, Inc., Chicago, IL).

\section{Results}

Genomic and Haplotype Structures of the DBP Gene

The DBP gene is at least $42 \mathrm{~kb}$ in length, contains 12 exons with a $4.3 \mathrm{~kb} \mathrm{3}$-UTR (see Fig. 1a), and has at least 295 SNPs according to dbSNP (build 129) [29]. We studied the LD structure of the DBP gene for the Caucasian population with SNP (minor allele frequency $>10 \%$ ) genotype data of the HapMap [24]. There are three LD blocks present in the DBP gene. Two SNPs, E416D and T420K in exon 11, are located in domain III (an osteoclast activating domain) and are genetically independent of LD block(s) in domain I (vitamin D binding domain). This suggests that these two SNPs in domain III might have genetic function(s) independent of other domains. Because of high linkage between these two SNPs, only three instead of the possible four haplotypes were present in our population, corresponding to three $\mathrm{Gc}$ isoforms distinguished at the protein level. The allele frequencies of the different haplotypes in the Rotterdam Study population are shown in Fig. $1 b$.

\section{Association Studies of DBP Haplotypes}

\section{Serum Vitamin D Level}

We measured serum vitamin $\mathrm{D}$ level in a subgroup $(n=1,317)$ of the Rotterdam Study. The vitamin D levels (mean and standard deviation $[\mathrm{SD}]$ ) of serum $25(\mathrm{OH}) \mathrm{D}_{3}$ and $1,25(\mathrm{OH})_{2} \mathrm{D}_{3}$ in our study population were $65.5 \pm 27.3 \mathrm{nmol} / \mathrm{l}$ and $109.3 \pm 30.3 \mathrm{pmol} / \mathrm{l}$, respectively (Table 1). Haplotype $1(\mathrm{Gc} 1 \mathrm{~s})$ is significantly associated with $7.4 \mathrm{nmol} / 1 \quad(0.3 \mathrm{SD})$ increased serum level of $25(\mathrm{OH}) \mathrm{D}_{3}\left(P=3 \times 10^{-4}\right.$ by a linear regression test for trend) and $8.4 \pm 0.3 \mathrm{pmol} / 11,25(\mathrm{OH})_{2} \mathrm{D}_{3}\left(P=4 \times 10^{-4}\right.$ for trend). In contrast, haplotype 2 (Gc2) is significantly associated with a $15.7 \pm 0.6 \mathrm{nmol} / 1$ decreased serum level of $25(\mathrm{OH}) \mathrm{D}_{3} \quad\left(P=3 \times 10^{-6}\right)$ and $7.3 \pm 0.2 \mathrm{pmol} / \mathrm{l}$ $1,25(\mathrm{OH})_{2} \mathrm{D}_{3}\left(P=5 \times 10^{-5}\right)$. The differences in serum vitamin $\mathrm{D}$ level between the noncarriers and carriers of haplotype alleles were from 0.2 to $0.6 \mathrm{SD}$. The associations were independent of age and gender. No significant difference in serum vitamin D level by haplotype3 (Gc1f) genotype was found.

\section{DBP Haplotypes and Fracture Risk}

No significant difference of fracture incidence was observed by DBP haplotypes, although we found a small increasing trend of fracture risk by DBP haplotype 1 $(P=0.13$ for dominant or additive genetic models, Table 2). The baseline characteristics by haplotype 1 of the DBP gene are shown in Table 3. In our study population, 
Table 1 Serum vitamin D level by haplotypes of DBP $(\mathrm{Gc})$ codon 416-420 in a subset of elderly men and women of the entire cohort

\begin{tabular}{|c|c|c|c|c|c|c|}
\hline & \multirow{2}{*}{$\begin{array}{l}\text { Mean } \pm \text { SD } \\
\text { (total number) }\end{array}$} & \multicolumn{3}{|c|}{ By haplotypes of DBP codon $416-420$} & \multirow{2}{*}{$\begin{array}{l}\text { Noncarrier vs. } \\
\text { homozygous } \\
\text { (SD) }\end{array}$} & \multirow[t]{2}{*}{$P^{\#}$} \\
\hline & & Noncarrier & Heterozygous & Homozygous & & \\
\hline $25-\mathrm{OH}-\mathrm{D}_{3}(\mathrm{nmol} / \mathrm{l})$ & $65.5 \pm 27.3(1312)$ & & & & & \\
\hline Hap 1 (Gc1 s) & & $61.1 \pm 26.3$ & $65.4 \pm 26.9(647)$ & $68.5 \pm 28.3$ & $\uparrow 0.3$ & $3 \times 10^{-4 *}$ \\
\hline Hap 2 (Gc2) & & $74.2 \pm 28.3(665)$ & $63.0 \pm 25.6(540)$ & $58.5 \pm 27.1$ & $\downarrow 0.6$ & $3 \times 10^{-6 *}$ \\
\hline Hap 3 (Gc1f) & & $65.0 \pm 27.2(917)$ & $66.7 \pm 27.6(360)$ & $64.9 \pm 27.1$ & $\downarrow 0.004$ & 0.57 \\
\hline $1,25-(\mathrm{OH})_{2}-\mathrm{D}_{3}(\mathrm{pmol} / \mathrm{l})$ & $109.3 \pm 30.3(1,317)$ & & & & & \\
\hline Hap $1(\mathrm{Gc} 1 \mathrm{~s})$ & & $103.7 \pm 29.1(270)$ & $109.8 \pm 30.8(648)$ & $112.4 \pm 29.9$ (399) & $\uparrow 0.3$ & $4 \times 10^{-4 *}$ \\
\hline Hap 2 (Gc2) & & $113.0 \pm 30.9(668)$ & $105.6 \pm 29.2(541)$ & $105.7 \pm 28.9$ & $\downarrow 0.2$ & $5 \times 10^{-5}$ \\
\hline Hap 3 (Gc1f) & & $108.9 \pm 29.7(922)$ & $111.0 \pm 31.5(360)$ & $102.0 \pm 32.2(35)$ & $\downarrow 0.2$ & 0.18 \\
\hline
\end{tabular}

Data are presented as mean \pm SD (number of subjects). Vitamin D level was adjusted for age and gender

\# $P$ value for trend (* estimated by linear regression analysis) and ANOVA

Table 2 Risk of fracture by DBP haplotypes of DBP codon 416-420 in 6,181 elderly individuals

\begin{tabular}{|c|c|c|c|c|c|}
\hline & \multirow[t]{2}{*}{ Total } & \multicolumn{3}{|c|}{ Haplotypes of DBP codon $416-420$} & \multirow[t]{2}{*}{$P$} \\
\hline & & Noncarrier & Heterozygous & Homozygous & \\
\hline \multicolumn{6}{|l|}{ Haplotype 1 (Gc1 s) } \\
\hline Case/total $(\%)$ & $905 / 6,181(14.6)$ & $155 / 1,183(13.1)$ & $456 / 3,068(14.9)$ & $294 / 1,930(15.2)$ & $0.13^{*}$ \\
\hline Crude HR $(95 \%$ CI $)$ & & 1 & $1.16(0.95-1.41)$ & $1.19(0.97-1.41)$ & $0.13^{*}$ \\
\hline Adjusted HR $(95 \% \mathrm{CI})^{\#}$ & & 1 & $1.13(0.93-1.38)$ & $1.20(0.97-1.49)$ & $0.13^{*}$ \\
\hline & & & \multicolumn{2}{|l|}{ Haplotype 1 carrier } & \\
\hline Case/total (\%) & & $155 / 1,183(13.1)$ & $750 / 4,998(15.0)$ & & 0.10 \\
\hline Adjusted HR $\left(95 \%\right.$ CI) ${ }^{\#}$ & & 1 & $1.16(0.96-1.40)$ & & 0.13 \\
\hline \multicolumn{6}{|l|}{ Haplotype 2 (Gc2) } \\
\hline Case/total (\%) & & $482 / 3,221(15.1)$ & $348 / 2,477(14.0)$ & $72 / 483(14.9)$ & 0.56 \\
\hline Crude HR (95\% CI) & & 1 & $0.92(0.80-1.07)$ & $0.99(0.76-1.29)$ & 0.56 \\
\hline Adjusted HR (95\% CI) & & 1 & $0.89(0.77-1.04)$ & $0.95(0.72-1.25)$ & 0.35 \\
\hline \multicolumn{6}{|l|}{ Haplotype 3 (Gc1f) } \\
\hline Case/total $(\%)$ & & $649 / 4,348(14.9)$ & $239 / 1,686(14.2)$ & 17/147 (11.6) & $0.24 *$ \\
\hline Crude HR (95\% CI) & & 1 & $0.94(0.80-1.10)$ & $0.74(0.45-1.24)$ & $0.24 *$ \\
\hline Adjusted HR (95\% CI) & & 1 & $0.95(0.81-1.12)$ & $0.84(0.50-1.42)$ & $0.42 *$ \\
\hline
\end{tabular}

\# HR was adjusted for age and gender

* Trend $P$ value estimated by linear regression analysis

we did not observe a relationship between DBP haplotype 1 genotype and age, gender, body height, weight, clinical fracture, and BMD.

\section{Interaction Between DBP and VDR Genotypes for Osteoporosis}

We investigated the interaction between DBP and VDR gene variants on the risk of osteoporosis in a regression model for fracture. The interaction $P$ value between the DBP and VDR genotypes in the relation to fracture risk was 0.015 . We therefore stratified the study population as noncarriers and carriers of DBP haplotype 1 (Table 4). In the group of DBP haplotype 1 carriers, the genetic effect of the VDR block 5-haplotype 1 on fracture risk remained and subjects homozygous for VDR block 5-haplotype 1 had a $32 \%$ increased fracture risk compared to noncarriers of this allele ( $P=0.008$ by the Cox model). This association was independent of age and gender. However, in subjects not carrying the DBP haplotype 1 allele, we did not observe an association between VDR block 5-haplotype 1 and fracture risk $(P=0.70)$. We did not achieve sufficient statistical power for analysis of this genetic interaction in the low and high calcium intake groups (data not shown). 
Table 3 Characteristics of the study population of 6,181 elderly men and women by DBP haplotype 1 (Gc1 s)

\begin{tabular}{|c|c|c|c|c|c|}
\hline \multirow[t]{2}{*}{ Characteristic $^{\mathrm{a}}$} & \multirow[t]{2}{*}{ Total cohort } & \multicolumn{3}{|c|}{ Haplotype 1 of DBP codon $416-420$} & \multirow[t]{2}{*}{$P$} \\
\hline & & Noncarrier & Heterozygous & Homozygous & \\
\hline Number ( $\%$ in entire cohort) & 6,181 & $1,183(19.1)$ & $3,068(49.6)$ & $1,930(31.2)$ & \\
\hline Female ( $\%$ of group) & 3,689 (59.7) & $703(59.4)$ & $1,831(59.7)$ & $1,155(59.8)$ & 0.97 \\
\hline Age (years) ${ }^{\mathrm{b}}$ & $69.4 \pm 9.1$ & $69.3 \pm 9.1$ & $69.7 \pm 9.3$ & $69.1 \pm 8.9$ & 0.07 \\
\hline Height $(\mathrm{cm})^{\mathrm{b}}$ & $166.8 \pm 9.5$ & $166.7 \pm 9.4$ & $166.6 \pm 9.5$ & $167.0 \pm 9.7$ & 0.11 \\
\hline Weight $(\mathrm{kg})^{\mathrm{b}}$ & $73.2 \pm 12.0$ & $73.2 \pm 12.3$ & $73.2 \pm 12.3$ & $73.0 \pm 11.5$ & 0.68 \\
\hline Dietary Ca intake $(\mathrm{g} / \mathrm{day})^{\mathrm{b}}$ & $1.13 \pm 0.36$ & $1.13 \pm 0.37$ & $1.13 \pm 0.36$ & $1.12 \pm 0.35$ & 0.36 \\
\hline Femoral neck BMD $\left(\mathrm{g} / \mathrm{cm}^{2}\right)^{\mathrm{b}}$ & $0.84 \pm 0.14$ & $0.84 \pm 0.13$ & $0.84 \pm 0.14$ & $0.84 \pm 0.14$ & 0.90 \\
\hline Lumbar spine BMD $\left(\mathrm{g} / \mathrm{cm}^{2}\right)^{\mathrm{b}}$ & $1.09 \pm 0.20$ & $1.10 \pm 0.20$ & $1.09 \pm 0.20$ & $1.09 \pm 0.19$ & 0.82 \\
\hline
\end{tabular}

${ }^{a}$ The following adjustments were applied: age, adjusted for gender; height, adjusted for age and gender; weight, adjusted for age, gender, and body height; dietary $\mathrm{Ca}$ intake, subset $n=4747$ adjusted for age, gender, and dietary energy intake; BMD, subset $n=5,027$ adjusted for age, gender, height, and weight

${ }^{\mathrm{b}}$ Data are presented as mean $\pm \mathrm{SD}$

\section{DBP Haplotype 1 and Dietary Calcium Intake in Osteoporosis}

In the subgroup ( $n=4,747)$ with a record of dietary calcium intake, we observed a similar trend (compared to the entire study population) and a borderline significant association of DBP haplotype 1 and fracture risk $(P=0.06)$. The interaction $P$ value between the DBP haplotype 1 genotype and dietary calcium intake for clinical fracture was 0.05 after adjustment for age and gender. We then investigated the relationship between DBP haplotype 1 and clinical fracture risk after stratification of the median dietary calcium intake. In the low dietary calcium intake ( $<1.09 \mathrm{~g}$ /day) group, we found that subjects homozygous for DBP haplotype $1(n=774)$ had $47 \%$ increased risk of clinical fracture compared to noncarriers $(n=439$, $P=0.02)$. The association remained when we adjusted for age and gender. In the high dietary calcium intake group no association was found. We also stratified calcium intake as tertiles and quartiles, and similar patterns of increased fracture risk by DBP haplotype 1 were observed in those with a relatively lower calcium intake (Fig. 2). No interaction between DBP genotype and calcium intake for BMD and serum vitamin D level was found.

No interaction between DBP or VDR genotypes in relation to vitamin $\mathrm{D}$ level or BMD was observed in our study population (data not shown).

\section{Discussion}

In this study we observed that haplotypes of DBP (corresponding to isoforms of Gc protein) are associated with differences in serum vitamin D level. In addition, we observed a genetic effect of the DBP gene on fracture risk, especially at low dietary calcium intake or in combination with an osteoporosis-risk allele of the VDR gene.

Together with other environmental and genetic factors, variation in DBP activity can contribute to the pathological progress of osteoporosis by the regulation of calcium metabolism in blood and bone. The protein and genomic structures reveal at least two separate functions of the DBP in bone remodeling. The vitamin $\mathrm{D}$ binding region of $\mathrm{DBP}$ is located between residues 35 and 49 at the N-terminal end (domain I in Fig. 1) [9]. Domains II and III are responsible for the non-sterol binding activities of DBP [15]. The macrophage/osteoclast activating activity is also related to domain III [14, 15]. The glycosylation of DBP in domain III is important for macrophage and osteoclast activation, while it has been shown that binding of vitamin $\mathrm{D}$ does not influence this activity [30]. This indicates that domain III plays an independent role from domain I (vitamin D binding domain) in the function of stimulating osteoclast activity. Two SNPs are located in the C-terminal end (domain III, from residue 375 to the end) with a single glycosylation site nearby. Our LD structure analysis of the DBP locus showed that domains I and III (the latter containing the two SNPs) are in different haplotype blocks. This indicates that all observed associations and interactions with the studied polymorphisms are independent of polymorphisms in the region corresponding to domain I.

The classical function of DBP is to store and prolong the half-life of circulating vitamin $\mathrm{D}$ metabolites. DBP binds 88 and $85 \%$ of serum $25(\mathrm{OH}) \mathrm{D}_{3}$ and $1,25(\mathrm{OH})_{2} \mathrm{D}_{3}$, respectively [9]. In our study, haplotype 1 (corresponding to $\mathrm{Gc} 1 \mathrm{~s})$ was positively correlated with both $25(\mathrm{OH}) \mathrm{D}_{3}$ and $1,25(\mathrm{OH})_{2} \mathrm{D}_{3}$, while haplotype $2(\mathrm{Gc} 2)$ was negatively correlated. Lauridsen et al. [31] demonstrated that Gc1 (consisting of $80 \%$ haplotype 1/Gc1s and $20 \%$ haplotype $3 / \mathrm{Gc1f}$ in our analysis) was associated with $8.5 \mathrm{nmol} / \mathrm{l}$ 
Table 4 Interaction between DBP haplotype 1 (Gc1s) and VDR block 5-haplotype 1 for the risk of clinical fracture

\begin{tabular}{|c|c|c|c|c|c|}
\hline & \multirow[t]{2}{*}{ Total } & \multicolumn{3}{|c|}{ Genotype of VDR block 5-haplotype 1} & \multirow[t]{2}{*}{$P$} \\
\hline & & Noncarrier & Heterozygous & Homozygous & \\
\hline \multicolumn{6}{|l|}{ Total study population } \\
\hline Case/total (\%) & $881 / 6,009(14.7)$ & 255/1,930 (13.2) & $428 / 2,887(14.8)$ & 198/1,192 (16.6) & 0.009 \\
\hline Crude HR $(95 \%$ CI $)$ & & 1 & $1.14(0.98-1.33)$ & $1.29(1.07-1.55)$ & $0.007^{\mathrm{c}}$ \\
\hline Adjusted HR $(95 \% \mathrm{CI})^{\mathrm{a}}$ & & 1 & $1.11(0.95-1.30)$ & $1.27(1.06-1.53)$ & $0.01^{\mathrm{c}}$ \\
\hline \multicolumn{6}{|l|}{ By DBP genotype } \\
\hline \multicolumn{6}{|l|}{ Carrier of DBP haplotype 1} \\
\hline Case/total $(\%)$ & $728 / 4,851(15.0)$ & 209/1,564 (13.4) & $351 / 2,321(15.1)$ & $168 / 966(17.4)$ & 0.006 \\
\hline Crude HR (95\% CI) & & 1 & $1.16(0.98-1.38)$ & $1.33(1.09-1.63)$ & $0.005^{\mathrm{c}}$ \\
\hline Adjusted HR (95\% CI) & & 1 & $1.14(0.96-1.35)$ & $1.32(1.07-1.61)$ & $0.008^{\mathrm{c}}$ \\
\hline \multicolumn{6}{|l|}{ Homozygous } \\
\hline Case/total $(\%)$ & $281 / 1592(15.0)$ & $82 / 529(13.4)$ & $137 / 761(15.3)$ & $62 / 302(17.0)$ & 0.12 \\
\hline Crude HR $(95 \% \mathrm{CI})$ & & 1 & $1.15(0.87-1.51)$ & $1.29(0.93-1.80)$ & $0.13^{\mathrm{c}}$ \\
\hline Adjusted HR (95\% CI) & & 1 & $1.12(0.81-1.56)$ & $1.25(0.81-1.56)$ & $0.26^{\mathrm{c}}$ \\
\hline \multicolumn{6}{|l|}{ Heterozygous } \\
\hline Case/total (\%) & $447 / 2531(15.0)$ & $127 / 826(13.3)$ & 214/1209 (15.0) & 106/496 (17.6) & 0.02 \\
\hline Crude HR (95\% CI) & & 1 & $1.17(0.94-1.46)$ & $1.36(1.05-1.76)$ & $0.02^{\mathrm{c}}$ \\
\hline Adjusted HR (95\% CI) & & 1 & $1.17(0.92-1.50)$ & $1.20(0.89-1.62)$ & $0.24^{\mathrm{c}}$ \\
\hline \multicolumn{6}{|c|}{ Noncarrier of DBP haplotype 1} \\
\hline Case/total $(\%)$ & $153 / 1158(13.2)$ & $46 / 366(12.6)$ & $77 / 566(13.6)$ & $30 / 226(13.3)$ & 0.90 \\
\hline Crude HR (95\% CI) & & 1 & $1.06(0.74-1.53)$ & $1.09(0.69-1.72)$ & $0.70^{\mathrm{c}}$ \\
\hline Adjusted HR $(95 \% \mathrm{CI})^{\mathrm{b}}$ & & 1 & $0.93(0.61-1.43)$ & $1.12(0.67-1.89)$ & $0.73^{\mathrm{c}}$ \\
\hline
\end{tabular}

${ }^{a}$ Subjects with DBP and VDR genotype data

${ }^{\mathrm{b}}$ HR was adjusted for age, gender, femeral neck and spine BMD, as well as BMI at baseline

c Trend $P$ value was estimated by Cox regression analysis

increased plasma $25(\mathrm{OH}) \mathrm{D}_{3}$ and DBP level in Danish Caucasian postmenopausal women, and DBP Gc2 was negatively correlated to plasma vitamin D and DBP level. Thus, our finding of a relationship between haplotype 1 and vitamin D level is in line with a previous report in Caucasians [12].

A relationship of $\mathrm{Gc} 1$ and increased fracture risk was reported by Lauridsen et al. [22, 31]. This relationship cannot be explained by the effect of DBP on the vitamin D endocrine system since increased total vitamin $\mathrm{D}$ is not associated with increased fracture risk. Only free vitamin $D$ hormone, which is only $<12-15 \%$ of the total vitamin D level, has biological activity, rather than bound hormone [32]. Thus, the observed relationship between DBP and fracture risk could result from the function of DBP-MAF in bone resorption.

We did not observe a significant association between DBP genotype and fracture risk in the complete study population, although a modest trend for DBP haplotype 1 $(\mathrm{Gc} 1 \mathrm{~s})$ associated with increased fracture risk $(P=0.13)$ was apparent. However, this association was stronger in subjects with relatively low dietary calcium intake
$(<1.09 \mathrm{~g} /$ day $)$ in this Dutch Caucasian population. We note that Lauridsen et al. [22] showed a similar relationship between Gc1 and fracture risk in a population of Danish Caucasians with a dietary calcium intake of $0.8 \mathrm{~g} /$ day level [31]. Another study, in a Japanese population [21], found the Glu allele at codon 416 (corresponding to our DBP haplotype 1) to be associated with decreased radial BMD. The dietary calcium intake of Japanese populations is considered to be even lower ( $0.6 \mathrm{~g} / \mathrm{day})$ [33] than ours and the Danish study populations. DBP haplotype 1 is associated with increased serum DBP level [31] and might also be associated with increased DBP-MAF level. DBP-MAF is an activator of osteoclasts, while in vivo studies have demonstrated that a calcium-deficient diet in rats could significantly increase the number of osteoclasts in different sites of bone [18, 19], which results in increasing bone resorption and releasing calcium into blood to maintain serum calcium at a stable level. We also analyzed subjects with dietary calcium intake $<0.6 \mathrm{~g} /$ day for DBP-related differences in BMD, but low statistical power in this small subgroup $(n=147)$ prevented any conclusion being drawn. 


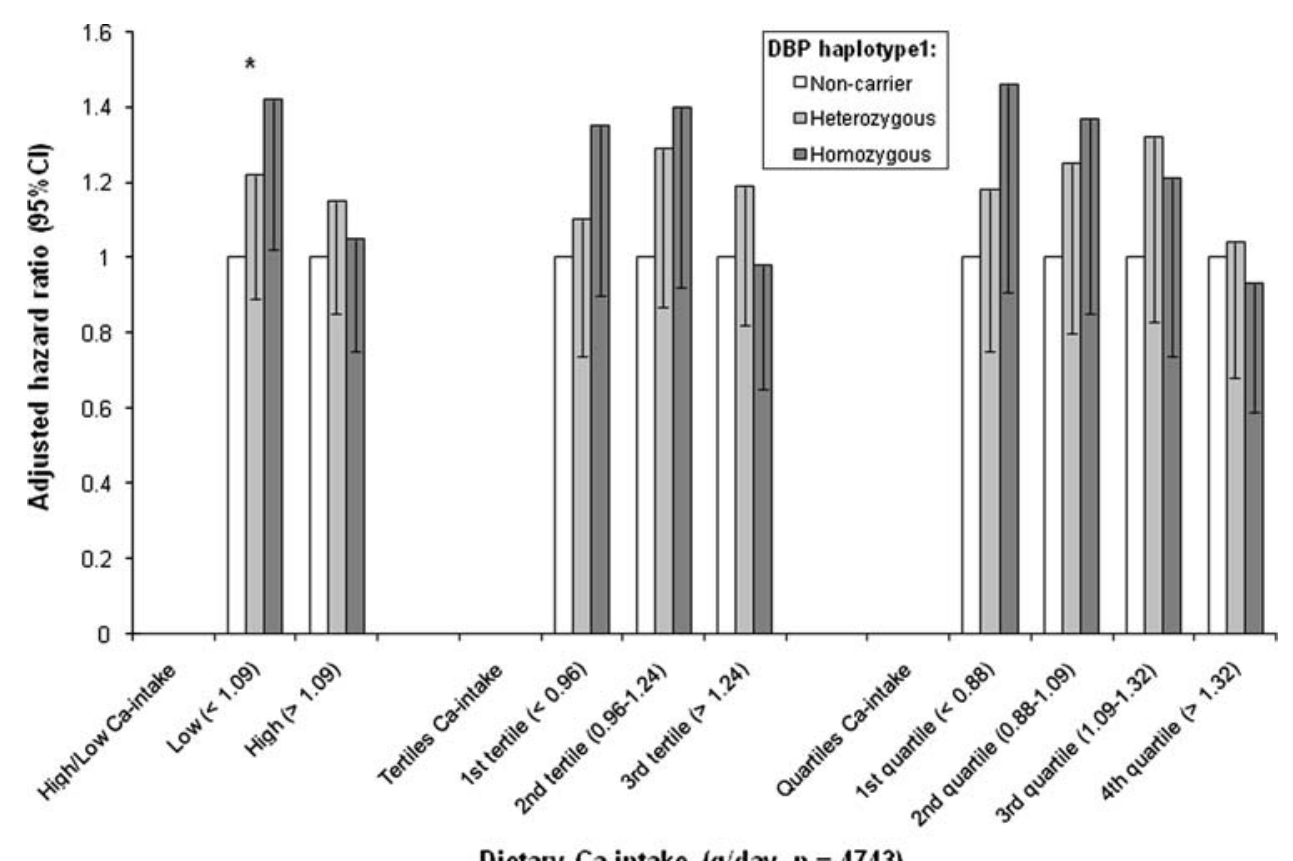

Fig. 2 Interaction of DBP haplotype 1 and dietary calcium intake for the risk of osteoporosis. We applied different ways to stratify calcium intake categories as median (low vs. high), tertiles, and quartiles. In each stratification analysis, the hazard ratio (adjusted for age and gender) was calculated by using noncarrier of DBP haplotype 1 as the reference category. In the low calcium intake $(<1.09 \mathrm{~g} /$ day $)$ group,

In this study we also demonstrated an association between VDR block 5-haplotype 1 and fracture risk, especially in the group of DBP haplotype 1 carriers. This gene-gene interaction on fracture risk reflects two aspects of bone (re)modeling, which include bone formation (by osteoblasts) and bone resorption (by osteoclasts) to maintain serum calcium homeostasis and bone metabolism. Vitamin D stimulates bone formation [34]. On the one hand, VDR block 5-haplotype 1, a fracture risk allele, results in lower expression of VDR mRNA in osteoblasts [13]. This indicates that the osteoblast of VDR block 5haplotype 1 carriers could give a compromised response to vitamin D since lower numbers of VDR protein are present in the target cells. This likely results in lower bone formation for VDR block 5-haplotype 1 carriers. On the other hand, DBP haplotype 1 is associated with increased DBP level, and this might result in increasing osteoclast activity and increasing bone resorption. Taken together, subjects with both fracture-risk alleles might have a lower bone formation and higher bone resorption and thereby increased bone turnover, which negatively influences bone quality and strength [35], with fracture risk consequently increasing. This hypothesis obviously needs to be tested by more detailed functionality studies.

We had excellent power $(100 \%)$ to detect our gene-gene and gene-environmental interaction effect on the fracture we observed that the clinical fracture risk increased with increased number of the DBP haplotype 1 and that those homozygous for DBP haplotype $1(n=774)$ had a $47 \%$ increased risk of fracture compared to noncarriers $(n=439, * P=0.02)$. A similar relationship between DBP haplotype 1 and clinical fracture was observed

risk in our large population. Although we did not observe an association of DBP genotype and fracture risk, we still had good statistical power $(>80 \%)$ to detect a real association if it existed in our studies. One limitation of the study was that, though most findings of our current study were from the same population, different findings were based on different subjects due to incomplete data for every individual in the large population.

We conclude that the genetic effect of the DBP haplotypes as defined by two SNPs (E416D and T420K) together with VDR genotype on fracture risk is independent of the vitamin D binding domain of the DBP protein. The modest genetic effect of the DBP gene on fracture risk is only apparent when other genetic (e.g., risk allele of the VDR gene) and environmental (e.g., low calcium intake) cofactors are present. This suggests that those genetic and environmental factors might affect bone turnover and consequently increase fracture risk.

Acknowledgements We thank all participants of the Rotterdam Study and the general practitioners, pharmacists, and many fieldworkers at the research center in the Netherlands. We thank C. J. Buurman for performing the serum vitamin D measurements. This project was funded by the Dutch Research Organisation (NWO 903-46-178, 925-01-010, 014-90-001, and 911-03-012) and the European Commission under grant QLK6-CT-2002-02629 (GENOMOS). 
Open Access This article is distributed under the terms of the Creative Commons Attribution Noncommercial License which permits any noncommercial use, distribution, and reproduction in any medium, provided the original author(s) and source are credited.

\section{References}

1. Ringe J (2004) Pathophysiology of postmenopausal osteoporosis, 1 st edn. Science Press, London

2. Uitterlinden AG, Pols HA, Burger H et al (1996) A large-scale population-based study of the association of vitamin D receptor gene polymorphisms with bone mineral density. J Bone Miner Res 11:1241-1248

3. Uitterlinden AG, Burger H, Huang Q et al (1998) Relation of alleles of the collagen type I alpha1 gene to bone density and the risk of osteoporotic fractures in postmenopausal women. N Engl J Med 338:1016-1021

4. van Meurs JB, Schuit SC, Weel AE et al (2003) Association of $5^{\prime}$ estrogen receptor alpha gene polymorphisms with bone mineral density, vertebral bone area and fracture risk. Hum Mol Genet 12:1745-1754

5. Fang Y, van Meurs JB, Bergink AP et al (2003) Cdx-2 polymorphism in the promoter region of the human vitamin $\mathrm{D}$ receptor gene determines susceptibility to fracture in the elderly. J Bone Miner Res 18:1632-1641

6. Murray RE, McGuigan F, Grant SF, Reid DM, Ralston SH (1997) Polymorphisms of the interleukin-6 gene are associated with bone mineral density. Bone 21:89-92

7. Ioannidis JP, Ralston SH, Bennett ST et al (2004) Differential genetic effects of ESR1 gene polymorphisms on osteoporosis outcomes. JAMA 292:2105-2114

8. Parfitt AM, Gallagher JC, Heaney RP, Johnston CC, Neer R, Whedon GD (1982) Vitamin D and bone health in the elderly. Am J Clin Nutr 36:1014-1031

9. White P, Cooke N (2000) The multifunctional properties and characteristics of vitamin D-binding protein. Trends Endocrinol Metab 11:320-327

10. Safadi FF, Thornton P, Magiera H et al (1999) Osteopathy and resistance to vitamin $\mathrm{D}$ toxicity in mice null for vitamin $\mathrm{D}$ binding protein. J Clin Invest 103:239-251

11. Grymonprez A, Proesmans W, Van Dyck M, Jans I, Goos G, Bouillon R (1995) Vitamin D metabolites in childhood nephrotic syndrome. Pediatr Nephrol 9:278-281

12. Bouillon R, Van Assche FA, Van Baelen H, Heyns W, De Moor $P$ (1981) Influence of the vitamin D-binding protein on the serum concentration of 1,25-dihydroxyvitamin D3. Significance of the free 1,25-dihydroxyvitamin D3 concentration. J Clin Invest 67:589-596

13. Fang Y, van Meurs JB, d'Alesio A et al (2005) Promoter and $3^{\prime}$ untranslated-region haplotypes in the vitamin $\mathrm{D}$ receptor gene predispose to osteoporotic fracture: the Rotterdam Study. Am J Hum Genet 77:807-823

14. Haddad JG (1995) Plasma vitamin D-binding protein (Gc-globulin): multiple tasks. J Steroid Biochem Mol Biol 53:579-582

15. Ray R (1996) Molecular recognition in vitamin D-binding protein. Proc Soc Exp Biol Med 212:305-312

16. Yamamoto N, Naraparaju VR, Orchard PJ (1996) Defective lymphocyte glycosidases in the macrophage activation cascade of juvenile osteopetrosis. Blood 88:1473-1478

17. Schneider GB, Benis KA, Flay NW, Ireland RA, Popoff SN (1995) Effects of vitamin D binding protein-macrophage activating factor (DBP-MAF) infusion on bone resorption in two osteopetrotic mutations. Bone 16:657-662

18. Liu CC, Baylink DJ (1984) Differential response in alveolar bone osteoclasts residing at two different bone sites. Calcif Tissue Int 36:182-188

19. Wright KR, McMillan PJ (1994) Osteoclast recruitment and modulation by calcium deficiency, fasting, and calcium supplementation in the rat. Calcif Tissue Int 54:62-68

20. Braun A, Bichlmaier R, Cleve H (1992) Molecular analysis of the gene for the human vitamin-D-binding protein (group-specific component): allelic differences of the common genetic GC types. Hum Genet 89:401-406

21. Ezura Y, Nakajima T, Kajita M et al (2003) Association of molecular variants, haplotypes, and linkage disequilibrium within the human vitamin D-binding protein (DBP) gene with postmenopausal bone mineral density. J Bone Miner Res 18:16421649

22. Lauridsen AL, Vestergaard P, Hermann AP, Moller HJ, Mosekilde L, Nexo E (2004) Female premenopausal fracture risk is associated with gc phenotype. J Bone Miner Res 19:875-881

23. Hofman A, Grobbee DE, de Jong PT, van den Ouweland FA (1991) Determinants of disease and disability in the elderly: the Rotterdam Elderly Study. Eur J Epidemiol 7:403-422

24. HapMap. http://www.hapmap.org/cgi-perl/gbrowse/gbrowse/hap map

25. Phase. http://archimedes.well.ox.ac.uk/pise/PHASE.html

26. Burger H, van Daele PL, Algra D et al (1994) The association between age and bone mineral density in men and women aged 55 years and over: the Rotterdam Study. Bone Miner 25:1-13

27. McCloskey EV, Spector TD, Eyres KS et al (1993) The assessment of vertebral deformity: a method for use in population studies and clinical trials. Osteoporos Int 3:138-147

28. Van der Klift M, De Laet CE, McCloskey EV, Hofman A, Pols HA (2002) The incidence of vertebral fractures in men and women: the Rotterdam Study. J Bone Miner Res 17:1051-1056

29. dbSNP. http://www.ncbi.nlm.nih.gov/entrez/query.fcgi?db=snp\& $\mathrm{cmd}=$ search\&term=human $+\mathrm{Gc}$

30. Swamy N, Ghosh S, Schneider GB, Ray R (2001) Baculovirusexpressed vitamin D-binding protein-macrophage activating factor (DBP-MAF) activates osteoclasts and binding of 25-hydroxyvitamin $\mathrm{D}_{3}$ does not influence this activity. J Cell Biochem 81:535-546

31. Lauridsen AL, Vestergaard P, Hermann AP et al (2005) Plasma concentrations of 25-hydroxy-vitamin D and 1,25-dihydroxyvitamin D are related to the phenotype of Gc (vitamin D-binding protein): a cross-sectional study on 595 early postmenopausal women. Calcif Tissue Int 77:15-22

32. Mendel CM (1989) The free hormone hypothesis: a physiologically based mathematical model. Endocr Rev 10:232-274

33. Tsuchida K, Mizushima S, Takahashi H, Misugi N, Soda K (1998) Relationship between dietary calcium and bone mineral density before menopause [in Japanese]. Nippon Koshu Eisei Zasshi 45:121-128

34. van Driel M, Koedam M, Buurman CJ et al (2006) Evidence for auto/paracrine actions of vitamin D in bone: 1alpha-hydroxylase expression and activity in human bone cells. FASEB J 20:24172419

35. Bauer DC, Black DM, Garnero P et al (2004) Change in bone turnover and hip, non-spine, and vertebral fracture in alendronatetreated women: the fracture intervention trial. J Bone Miner Res 19:1250-1258 